\title{
Prediction of outcome of tubal ectopic pregnancy on the basis of site of implantation of embryo in the fallopian tube
}

\author{
Rajshree D. Katke*, Ashique Shaikh
}

\begin{abstract}
Department of Obstetrics \& Gynaecology, Grant Government Medical College \& Sir J. J. Group of Hospitals, Mumbai, Maharashtra, India
\end{abstract}

Received: 06 August 2015

Revised: 09 September 2015

Accepted: 12 September 2015

\section{*Correspondence:}

Dr. Rajshree D. Katke,

E-mail: drrajshrikatke@gmail.com

Copyright: (C) the author(s), publisher and licensee Medip Academy. This is an open-access article distributed under the terms of the Creative Commons Attribution Non-Commercial License, which permits unrestricted non-commercial use, distribution, and reproduction in any medium, provided the original work is properly cited.

\begin{abstract}
Background: Ectopic pregnancy is a high-risk condition that occurs in 1.9 percent of reported pregnancies. The condition is the leading cause of pregnancy-related death in the first trimester. If a woman of reproductive age presents with abdominal pain, vaginal bleeding, syncope, or hypotension, the physician should perform a pregnancy test. If the patient is pregnant, the physician should perform a work-up to detect possible ectopic or ruptured ectopic pregnancy.

Methods: This study was an observational analytical type of study in which all the diagnosed cases of tubal ectopic were included. Detailed history and clinical evaluation was done and information was collected in a pre-tested proforma. Data was analyzed by frequency, percentages and chi square test.

Results: In this study total 50 cases were studied. In this we found a significant correlation between site of implantation in tubal ectopic and its final outcome.

Conclusions: Early detection of tubal ectopic and its site of implantation can help in deciding further management especially to go for conservative or surgical management.
\end{abstract}

Keywords: Ectopic pregnancy, Implantation

\section{INTRODUCTION}

Following fertilization and fallopian tube transit, the blastocyst normally implants in the endometrial lining of the uterine cavity. Implantation elsewhere is considered ectopic and comprises 1 to 2 percent of all first-trimester pregnancies in the United States. ${ }^{1}$ This small proportion disparately accounts for 6 percent of all pregnancyrelated deaths. ${ }^{2,3}$ In addition, the chance for a subsequent successful pregnancy is reduced after an ectopic pregnancy

Nearly 95 percent of ectopic pregnancies are implanted in the various segments of the fallopian tube and give rise to ampullary $(70 \%)$, isthmic $(12 \%)$, fimbrial $(11 \%)$ or interstitial (2-3\%) tubal pregnancies. ${ }^{4}$

With tubal pregnancy, because the fallopian tube lacks a sub- mucosal layer, the fertilized ovum promptly burrows through the epithelium. The zygote comes to lie near or within the mascularis, which is invaded in most cases by rapidly proliferating trophoblast.

Outcomes of ectopic pregnancy include tubal rupture, tubal abortion, or pregnancy failure with resolution. With rupture, the invading expanding products of conception and associated hemorrhage may tear rents in the fallopian tube at any of several sites. As a rule, if the tube ruptures in the first few weeks, the pregnancy is most likely 
located in the isthmic portion, whereas the ampulla is slightly more distensible. However, if the fertilized ovum implants within the interstitial portion, rupture usually occurs later. Tubal ectopic pregnancies usually burst spontaneously but may occasionally rupture following coitus or bimanual examination. Alternatively, the pregnancy may abort out the distal fallopian tube, and the frequency of this depends in part on the initial implantation site. Abortion is common in fimbrial and ampullary pregnancies, whereas rupture is the usual outcome with those in the tubal isthmus4. With tubal abortion, hemorrhage disrupts the connection between the placenta and membranes and the tubal wall. If placental separation is complete, the entire conceptus may be extruded through the fimbriated end into the peritoneal cavity. At this point, hemorrhage may cease and symptoms eventually disappear. Some bleeding usually persists as long as products remain in the tube. Blood slowly trickles from the tubal fimbria into the peritoneal cavity and typically pools in the rectouterine cul-de-sac (Figure 1).

The term tubal abortion is also used when an intact, viable pregnancy is surgically removed during an operative intervention in an ectopic pregnancy. Tubal abortion can follow several courses: resorption of the products of conception; intraluminal extension with expulsion of gestational products; and perforation and rupture into the peritoneal cavity. ${ }^{5}$

In the present study we tried to evaluate the outcome for tubal ectopic pregnancies based on their site of implantation.

\section{METHODS}

We conducted an observational analytical study of all the cases of ectopic pregnancies admitted to our hospital between August 2013 and December 2014 after obtaining clearance from the Hospital Ethical Committee. The details of maternal characteristics, clinical presentation, management and complications of the condition were noted from the case records. All the observations were documented and results tabulated. There were total 50 cases of ectopic pregnancy. The diagnosis of cases was based on clinical evaluation followed by a pelvic ultrasound scan.

\section{RESULTS}

\section{Site of ectopic pregnancy}

The ampulla of the tube had the most number of ectopic pregnancies (68\%) followed by isthmus, fimbria and cornua. We had 2 cases of ovarian ectopic pregnancies amounting to $4 \%$ of all ectopics.
Table 1: Site of ectopic pregnancy.

\begin{tabular}{|lll|}
\hline $\begin{array}{l}\text { Site of Ectopic } \\
\text { Pregnancy }\end{array}$ & Number & Percentage \\
\hline Ampulla & 34 & $68.0 \%$ \\
\hline Isthmus & 5 & $10.0 \%$ \\
\hline Fimbrial & 4 & $8.0 \%$ \\
\hline Cornual & 1 & $2.0 \%$ \\
\hline Ampulla + Isthmus & 4 & $8.0 \%$ \\
\hline Ovary & 2 & $4.0 \%$ \\
\hline Total & 50 & $100.0 \%$ \\
\hline
\end{tabular}

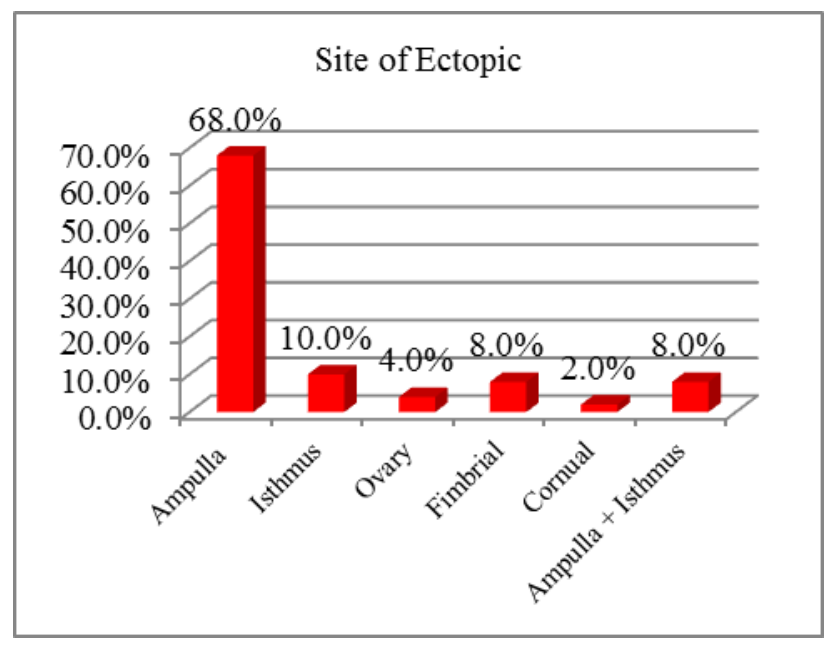

Figure 1: Incidence of site of ectopic.

\section{Outcome of the ectopic pregnancy}

We had three main outcomes viz. ruptured, unruptured or tubal abortion.

Ruptured ectopic pregnancies amounted to $48 \%$ followed by unruptured and tubal abortion, each amounting to $26 \%$.

Table 2: Outcome of the ectopic pregnancy.

\begin{tabular}{|lll|}
\hline Outcome & N & $\%$ \\
\hline Ruptured & 24 & $48 \%$ \\
\hline Tubal Abortion & 13 & $26 \%$ \\
\hline Unruptured & 13 & $26 \%$ \\
\hline Total & 50 & $100.0 \%$ \\
\hline
\end{tabular}

Correlation of site of ectopic pregnancy with the outcome of pregnancy

$34 \%$ of the ampullary pregnancies ruptured, $18 \%$ aborted whereas $16 \%$ were left unruptured.

All fimbrial pregnancies ( $8 \%$ of total) underwent tubal abortions. When the same was compared with ampullary pregnancies, a statistically significant correlation was found $(\mathrm{p}=0.0261$ at $95 \%$ Confidence Interval = $0.8031 / 342.2)$. 
All ovarian pregnancies (4\% of total) underwent rupture, however, no statistical significance was found on comparing with ampullary pregnancies $(\mathrm{p}=1.000)$.

Only 1 cornual pregnancy was observed in our study ( $2 \%$ of total) which was unruptured on diagnosis $(\mathrm{p}=0.3462)$.

When unruptured ecpregnancies were considered (26\%), none had a statistically significance with the site of the ectopic pregnancy (Figure 2).

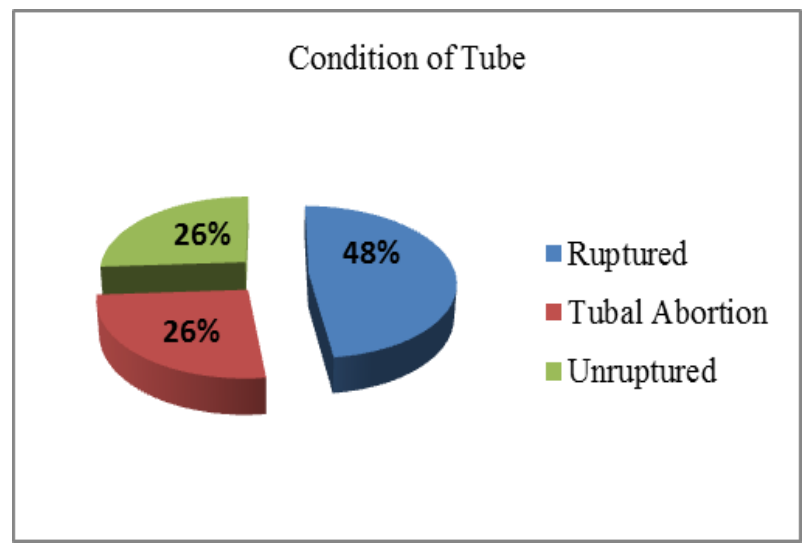

Figure 2: Condition of fallopian tube.

Table 3A: Correlation of site of ectopic pregnancy with the outcome of pregnancy.

\begin{tabular}{|c|c|c|c|c|}
\hline \multirow{2}{*}{$\begin{array}{l}\text { Site of } \\
\text { Ectopic } \\
\text { Pregnancy }\end{array}$} & \multicolumn{3}{|c|}{ Condition of Tube } & \multirow[b]{2}{*}{ Total } \\
\hline & Ruptured & $\begin{array}{l}\text { Tubal } \\
\text { Abortion }\end{array}$ & Un ruptured & \\
\hline Ampulla & $\begin{array}{l}17 \\
(34 \%)\end{array}$ & $\begin{array}{l}9 \\
(18 \%)\end{array}$ & $\begin{array}{l}8 \\
(16 \%)\end{array}$ & $\begin{array}{l}34 \\
(68 \%)\end{array}$ \\
\hline Isthmus & $\begin{array}{l}3 \\
(6 \%)\end{array}$ & 0 & $\begin{array}{l}2 \\
(4 \%)\end{array}$ & $\begin{array}{l}5 \\
(10 \%)\end{array}$ \\
\hline Ovary & $2(4 \%)$ & 0 & 0 & $\begin{array}{l}2 \\
(4 \%)\end{array}$ \\
\hline Fimbrial & 0 & $\begin{array}{l}4 \\
(8 \%)\end{array}$ & 0 & $\begin{array}{l}4 \\
(8 \%)\end{array}$ \\
\hline Cornual & 0 & 0 & $\begin{array}{l}1 \\
(2 \%)\end{array}$ & $\begin{array}{l}1 \\
(2 \%)\end{array}$ \\
\hline $\begin{array}{l}\text { Ampulla + } \\
\text { Isthmus }\end{array}$ & $2(4 \%)$ & 0 & $\begin{array}{l}2 \\
(4 \%)\end{array}$ & $\begin{array}{l}4 \\
(8 \%)\end{array}$ \\
\hline Total & $\begin{array}{l}24 \\
(48 \%)\end{array}$ & $\begin{array}{l}13 \\
(26 \%)\end{array}$ & $\begin{array}{l}13 \\
(26 \%)\end{array}$ & $\begin{array}{l}50 \\
(100 \%)\end{array}$ \\
\hline
\end{tabular}

\section{DISCUSSION}

Effective transport of embryos in the fallopian tube requires a delicately regulated complex interaction between the tubal epithelium, tubal fluid, and tubal contents. This interaction ultimately generates a mechanical force, composed of tubal peristalsis, ciliary motion, and tubal fluid flow, to drive the embryo towards the uterine cavity. This process is subject to dysfunction at many different points that can ultimately manifest as ectopic pregnancy.
Oocyte migration difficulty is most often associated with abnormal fallopian tube anatomy. This can result from tubal pathology (e.g., chronic salpingitis, salpingitis isthmica nodosa), tubal surgery (e.g. reconstruction, sterilization), or in utero DES exposure. It is thought that alterations in molecular signaling between the oocyte and the implantation site may make an ectopic pregnancy more likely. A number of molecular factors are under investigation for possible involvement in premature implantation. These factors include cellular and extracellular matrix proteins such as lectin, integrin, matrix-degrading cumulus, prostaglandins, growth factors, and cytokines.

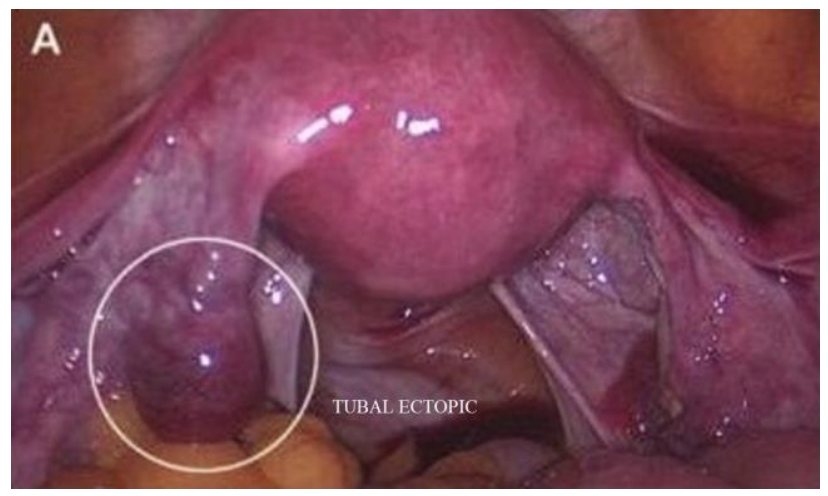

Figure 3: Tubal ectopic.

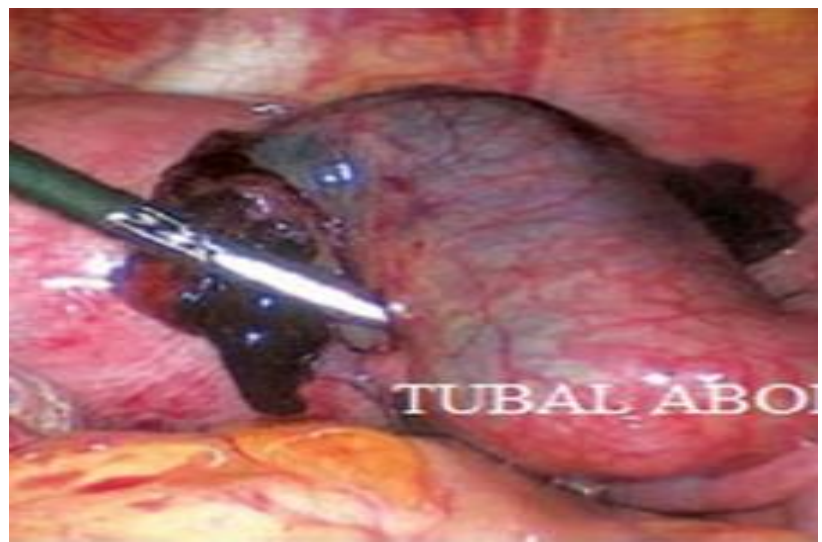

Figure 4: Tubal abortion.

Various ways in which termination of tubal ectopic may occur is elaborated below:

1. Tubal abortion may result in: common mode of termination if implantation occurs in the ampulla or infundibulum.

a. Complete resorption without residual tubal damage and is essentially asymptomatic though it is difficult to prove.

b. Complete abortion: The pregnancy sac is extruded by tubal contractions through the abdominal ostium into the peritoneal cavity. If the ovum is small and the abortion is accompanied by only slight bleeding, the symptoms may be unimpressive and the pregnancy may be completely absorbed. 
c. Incomplete abortion: Here the products of conception reach the abdominal ostium but are only partially discharged through it. Intratubal or peritoneal reimplantation of the abortus may result from this accident. Some authorities feel that regrowth of such an abortus is probably impossible.

d. Missed abortion (tubalmole): The dead ovum may remain in the tube and be subjected to repeated small chorio-decidual hemorrhages', which convert it into a carneous mole .If the pregnancy is small, the process can become arrested. The mole is then partly absorbed and partly liquefied to give rise to a small and often symptomless haematosalpinx.

\section{Tubal Rupture}

This outcome is less common than tubal abortion .It is mostly seen when the pregnancy is implanted in the isthmus or interstitial part of the tube where the lumen is narrow and incapable of much distension. The ovum burrows deeply and ultimately erodes through the tube wall. The final break is the result of both distension and erosion and may be sudden. In the process, large arterioles are usually ruptured. The Pregnancy may be completely discharged through the rent; the tube can then retract and arrest the bleeding. More often the pregnancy is only partly extruded, chorionic villi alone may protrude and the bleeding is then heavy and recurrent. Isthmic rupture usually occurs at 6-8weeks, the ampullary one at $8-12$ weeks and the interstitial one at about $4^{\text {th }}$ month. Rupture can be intraligamentary or intraperitoneal: Intraligamentary (extraperitoneal) rupture: is rare and is accounted for by rupture.

Table 3B: Correlation of site of ectopic pregnancy with the outcome of pregnancy.

\begin{tabular}{|llllll|}
$\begin{array}{l}\text { Site of } \\
\text { pregnancy }\end{array}$ & $\begin{array}{l}\text { Outcome of pregnancy } \\
\text { Ruptured }\end{array}$ & Unruptured & p value & Odds ratio & $\begin{array}{l}95 \% \text { Confidence } \\
\text { Interval }\end{array}$ \\
\hline Ampulla & 17 & 8 & & & \\
\hline Isthmus & 3 & 2 & $1.0000^{*}$ & $1.417^{*}$ & 0.1961 to $10.23^{*}$ \\
\hline Ovary & 2 & 0 & $1.0000^{* * *}$ & $0.4118^{* * *}$ & 0.01772 to $9.568^{* *}$ \\
\hline Cornual & 0 & 1 & $0.3462^{* * *}$ & $6.176^{* * *}$ & 0.2267 to $168.2^{* * *}$ \\
\hline${ }^{*}$ Comparing Ampulla with Isthmus; ${ }^{* *}$ Comparing Ampulla with Ovary; ${ }^{* * *}$ Comparing Ampulla with Cornu \\
\hline
\end{tabular}

Table 3C: Correlation of site of ectopic pregnancy with the outcome of pregnancy.

\begin{tabular}{|c|c|c|c|c|c|}
\hline \multirow{2}{*}{$\begin{array}{l}\text { Site of } \\
\text { pregnancy }\end{array}$} & \multicolumn{5}{|c|}{ Outcome of pregnancy } \\
\hline & Ruptured & Tubal Abortion & p value & Odds ratio & 95\% Confidence Interval \\
\hline Ampulla & 17 & 9 & & & \\
\hline Isthmus & 3 & 0 & $0.532^{\#}$ & $0.2632^{\#}$ & 0.01225 to $5.654^{\#}$ \\
\hline Ovary & 2 & 0 & $1^{\#}$ & $0.3684^{\#}$ & 0.01598 to $8.497^{\# \#}$ \\
\hline Fimbrial & 0 & 4 & $0.0261^{\text {\#\#\# }}$ & $16.58^{\# \#}$ & 0.8031 to $342.2^{\# \# \#}$ \\
\hline
\end{tabular}

The tube at the point where it is attached to the broad ligament. The pregnancy and the blood are then discharged between the layers of the broad ligament to form a pelvic or broad ligament haematoma. Ultimately one leaf of the broad ligament may give way under the strain of recurrent hemorrhage and a secondary intraperitoneal rupture occurs.

Intraperitoneal rupture: Usually occurs towards the peritoneal cavity and the blood collects there in a partly solid but mainly fluid form. Dramatic signs due to acute blood loss accompany it .If the patient survives this insult without surgical intervention, reimplantation may occur. The blood will collect to form a pelvic haematocoele. Occasionally, if the conceptus is larger, it may remain in cul-de-sac for years as an encapsulated mass or even become calcified to form a lithopaedian.

3. Viable intra tubal pregnancy many unruptured viable pregnancies are removed intact. Although a majority of these would rupture or abort, a few cases where live infant shave been delivered by abdominal section have been recorded. ${ }^{6}$

4. To justify such a case as a true tubal gestation, the wall of the appendage must be intact and surround the gestational sac.

5. Intrauterine extrusion with result ant term pregnancy, abortion or rupture. 
6. Chronic ectopic ("Obscure", "delayed" or "occult" tubal rupture) In this situation, the pregnancy dies but a variation of "Death in utero" takes place with mild chronic symptoms often dominated by anemia. Slow leakage of blood around the adnexa for msa pelvic mass often misdiagnosed as inflammatory disease. Resorption may take place but usually the patient is treated surgically if the mass is discovered.

Table 4: Outcome of the ectopic pregnancy.

\begin{tabular}{|lll|}
\hline Outcome & $\begin{array}{l}\text { Savitha Devi } \\
(2000)^{8}\end{array}$ & Present study \\
\hline Ruptured & $30.77 \%$ & $48 \%$ \\
\hline Unruptured & $69.23 \%$ & $26 \%$ \\
\hline
\end{tabular}

Table 5: Site of ectopic pregnancy.

\begin{tabular}{|ccccc|}
$\begin{array}{c}\text { Site of } \\
\text { ectopic } \\
\text { pregnancy }\end{array}$ & $\begin{array}{c}\text { Khera } \\
(\mathbf{1 9 8 8})^{9}\end{array}$ & $\begin{array}{c}\text { Savitha } \\
\text { Devi } \\
(2000)^{7}\end{array}$ & $\begin{array}{c}\text { K. } \\
\text { Sarada } \\
\text { Bai }^{10} \\
(2014)\end{array}$ & $\begin{array}{c}\text { Present } \\
\text { study }\end{array}$ \\
\hline Ampullary & $71.7 \%$ & $61.53 \%$ & $68.7 \%$ & $68 \%$ \\
\hline Ishmal & $20.75 \%$ & $13.46 \%$ & $7.8 \%$ & $10 \%$ \\
\hline Interstitial & $5.66 \%$ & - & $3.9 \%$ & $0 \%$ \\
\hline Ovarian & - & $1.92 \%$ & $4.7 \%$ & $4 \%$ \\
\hline Fimbrial & - & - & - & $8 \%$ \\
\hline
\end{tabular}

Wills et al in their study found the incidence of ruptured and unruptured ectopic to be $66 \%$ and $34 \%$ respectively. In our study the percentage of ruptured and unruptured ectopic was $48 \%$ and $26 \%$ respectively.

Ectopic pregnancy can occur at any time from menarche to menopause. It can either present as a case of bleeding $\mathrm{PV}$ or as an obstetric emergency. Tubal rupture cannot be predicted on the basis of any known risk factor, ultra sonogram findings, or serum hCG levels. ${ }^{7}$ However it is a known fact that pregnancy implanted at the ampullary as well as isthmic part of the fallopian tube have a greater risk of tubal rupture. Which among the two is at a greater risk, could not predicted by our study $(\mathrm{p}=1.0000)$.

\section{CONCLUSIONS}

Ectopic pregnancy still poses a great risk to maternal health and is one of the leading causes of maternal morbidity and mortality. In the modern era of imaging modalities it is very important to get it diagnose ectopic pregnancy at earliest of gestation but still majority of patients come with complications like ruptured ectopic. Early diagnosis and treatment remains the crucial part in the management strategy. Knowledge about the site of tubal pregnancy may guide the clinician regarding the nature of the outcome of the ectopic pregnancy. Good clinical judgement along with the availability of quick Ultrasound facilities helps in early treatment initiation and thus decreases the immediate as well as late complications of ectopic pregnancy.

\section{CONCLUSIONS}

The authors would be thankful to Dr. Ashish S. Waje and Dr. Pranay Desai from Grant govt. Medical College and JJ group of hospitals, Mumbai.

Funding: No funding sources

Conflict of interest: None declared

Ethical approval: The study was approved by the Institutional Ethics Committee

\section{REFERENCES}

1. Williams Obstetrics $24^{\text {th }}$ E. Ectopic Pregnancy. Chapter No. 19. Pg. 377.

2. Berg CJ, Callaghan WM, Syverson C, et al. Pregnancy-related mortality in the United States, 1998-2005. Obstet Gynecol. 2010;116:1302.

3. Stulberg DB, Cain LR, Dahlquist I, et al: Ectopic pregnancy rates in the Medicaid population. Am J Obstet Gynecol. 2013;208(4):274.e1.

4. Williams Obstetrics $24^{\text {th }}$ E. Ectopic Pregnancy. Chapter No. 19. Pg. 378

5. Caspi E, Sherman D. Tubal abortion and infundibular ectopic pregnancy. Clin Obstet Gynecol. 1987;30(1):155-63.

6. Gunnar U. A case of fimbrial pregnancy at term with delivery of a living child. Acta obstetricia et gynecologica Scandinavica 39.1. 1960:131-42.

7. Falcone T, Mascha EJ, Goldberg JM, Falconi LL, Mohla G, Attaran M. A study of risk factors for ruptured tubal ectopic pregnancy. J Womens Health. 1998;7(4):459-63.

8. Devi S. Laparoscopic Treatment of Ectopic Pregnancy. Journal of Obs and Gyn of India. 2000;50:69.

9. Khera KR. The Journal of Obstetrics and Gyn of India, 1988;38(1):49.

10. Bai KS, Sujatha R. A Study of Incidence, Clinical Presentation and Risk Factors Associated with Ectopic Pregnancy. Journal of Evidence based Medicine and Healthcare. 2015:2922-30.

Cite this article as: Katke RD, Shaikh A. Prediction of outcome of tubal ectopic pregnancy on the basis of site of implantation of embryo in the fallopian tube. Int J Reprod Contracept Obstet Gynecol 2015;4:1431-5. 